\title{
Research on Marketing of Agricultural Products in Xiaoliang Mountain from the Perspective of Precision Poverty Alleviation
}

\author{
Deng Jian \\ School of Economics and Management \\ Leshan Teachers College \\ Sichuan Province
}

\author{
Zhang Congfang \\ School of Economics and Management \\ Leshan Teachers College \\ Sichuan Province
}

\author{
Ren He \\ Chengdu Modern Agriculture Finance Guarantee Co., Ltd.
}

\begin{abstract}
At the 18th National Congress of the Communist Party of China, it was proposed to build a comprehensive well-off society. Since then, the poverty alleviation work in the Xiaoliang Mountain area of Sichuan has been raised to the national strategic level. In recent years, agricultural production in this area has been greatly developed after poverty alleviation. However, due to the lack of suitable marketing strategies for agricultural products, the problem of difficult sales of agricultural products has become a bottleneck for poverty alleviation and prosperity in this area. This paper analyzes the marketing dilemma of Xiaoliang Mountain's agricultural products, and puts forward some suggestions to improve the precision of poverty alleviation through reasonable selection of target market, innovative product strategy, brand strategy, packaging strategy, price strategy, channel strategy and promotion strategy.
\end{abstract}

Keywords-Targeted poverty alleviation; Xiaoliang Mountain's agricultural products; marketing strategy

\section{INTRODUCTION}

Xiaoliang Mountain refers to the three districts and counties of Mabian Yi Autonomous County, Yibian Yi Autonomous County and Jinkouhe Autonomous Region in Leshan City, Sichuan Province. Due to geographical and historical conditions, the local economic development level is backward and it is a national poverty-stricken county. After the report of the 18th National Congress of the Communist Party of China first put forward the idea of building a well-off society in an all-round way, Xiaoliang Mountain's poverty alleviation work has been raised to a national strategic height. With the implementation of the road construction subsidies, the support of the construction of the Yi stock, the strengthening of tourism construction in the urban areas, and the support for the special funds for the development of precision poverty reduction industries in Xiaoliang Mountain, increased poverty alleviation work in the region by the Sichuan Provincial Government and Leshan City, a large amount of people and property invested and a modern and characteristic technology demonstration base established, local farmers also planted Chinese herbal medicines, tobacco, tea and other crops in addition to planting traditional crops, and Xiaoliang Mountain's agricultural production has developed considerably.

At present, the production of agricultural products in Xiaoliang Mountain has a certain scale, but it is difficult to sell. Farmers are trapped in the dilemma of "increasing production without increasing income", which greatly reduces the effect of poverty alleviation. The sale of agricultural products has become a bottleneck restricting the region from poverty alleviation to prosperity. Therefore, how to sell Xiaoliang Mountain's agricultural products to help farmers both increase production and income is the Xiaoliang Mountain accurate poverty alleviation problem to be solved urgently.

\section{Difficulties of Saling Xiaoliang Mountain Agricultural PRODUCTS}

\section{A. Lack of Popularity}

In the sales process of small Xiaoliang Mountain agricultural products, the improvement of sales volume are emphasized but brand building are neglected. At present, although some agricultural products have established a "processing + marketing" model, enterprises purchase raw materials from farmers, and then processing, but the final product is the brand of processing enterprises, rather than the name of Xiaoliang Mountain agricultural products. And because the local farmers are poorly educated, they are only concerned about selling what they grow, ignoring the impact of the brand. The traditional sales model coupled with the neglect of regional brand building has led to the fact that Xiaoliang Mountain's agricultural products are not well known to consumers. And because of the lack of brand awareness, Xiaoliang Mountain's agricultural products stay in the weak side in the process of cooperation with processing enterprises and have little voice and bargaining power in the acquisition price, which indirectly leads to the 'high yield and low income situation" of farmers. 


\section{B. Less Certified Agricultural Products}

Agricultural product certification began in the early 20th century in the United States. With the increase of industrial processing, food safety has become a potential threat to human health. Agricultural product certification can ensure the quality and safety of agricultural products. At present, China's certified agricultural products are mainly divided into three categories: pollution-free agricultural products, green agricultural products and organic agricultural products. Because of its special geographical location, Xiaoliang Mountain has fewer factories and almost no environmental pollution. It is a pure land. Most of its agricultural products are green and organic. However, due to the local economic, social constraints and traffic conditions and blocked information, farmers in the region lack the awareness of agricultural products certification, so they can not get premium for the sale of high-quality agricultural products.

\section{Backward Traffic Condition}

Xiaoliang Mountain area is mostly high mountains and deep valleys and it is also minority areas. The slow development of local economy led to the construction of local transport infrastructure lags far behind other areas. After three years of poverty alleviation, although the Xiaoliang Mountain Township has basically achieved a highway, there is almost no road to the home for farmers living in the elevation, it's difficult for people to go out of the mountain is very inconvenient. Agricultural products, which are not exported to the outside world, are often spoiled in the fields.

\section{Agricultural Products Lack of Modern Technology Guidance}

First of all, due to geographical reasons and traffic congestion, the local people do not know much about the modern technology of farm produce cultivation outside. Secondly, the local people are generally less educated, lack of understanding and systematic learning of the science and technology of agricultural production cultivation. Although the state has implemented the industrial poverty alleviation policy at present, 1-2 agricultural technicians are deployed in each township to guide farmers in their production and cultivation, and at the same time to teach farmers the techniques of planting and breeding, however, due to the fact that most of the local people are Yi people, the agricultural technicians have obstacles in communication with the farmers, which leads to the traditional breeding methods in the local breeding industry. Without the use of modern agricultural technology, it has restricted the production of local agricultural products to a certain extent, resulting in low economic income of farmers.

\section{E. Single Sales Channel}

At present, the main sales channel in Xiaoliang Mountain area is individual sales, which is caused by local geographical and cultural factors, and can not change this situation in a short time. The marketing mode of factory processing mainly concentrates on the construction of production base, which can not benefit most farmers. The Internet has not yet achieved full coverage in mountain areas, and many farmers are skeptical of online sales, making the promotion of this marketing model more difficult. This single marketing model in Xiaoliang Mountain area has shown its drawbacks in the Internet era, such as small sales radiation, high cost of time, unable to accurately grasp market information and so on, which have become the disadvantages of agricultural products sales.

\section{Agricultural Products Sales Strategy in XiaOliang Mountain}

Most of the Xiaoliang Mountain area is alpine canyon, 95\% of the area is mountainous, the altitude difference is large, and this terrain is very suitable for the production of seasonal agricultural products. In addition, the blocked traffic conditions make many factories unwilling to move into the area, which protects the local environment in disguise. Xiaoliang Mountain currently preserves many national nature reserves such as Heizhugou and Dafengding. A natural, pollution-free environment provides conditions for the production of organic and green produce. The Xiaoliang Mountain area should seize the consumer's thirst for green and organic agricultural products and the opportunity of the country's precise poverty alleviation. Through innovative marketing models, the brand of Xiaoliang Mountain agricultural products will be built to achieve poverty alleviation.

\section{A. Reasonable Choice of Target Market}

Xiaoliang Mountain's farm products will cost more because of their quality and inconvenience in transportation. Therefore, its main target market should be targeted at the middle and high-end groups. In terms of market choice, the primary market for Xiaoliang Mountain's agricultural products is Chengdu, because the region is economically developed, with a large population density and a large demand for green and pollutionfree agricultural products. As a primary market, the area has great room. The secondary market is Leshan, and Xiaoliang Mountain is a municipality directly under the central government of Leshan. With the opening of the Emei-han Expressway, the distance between Xiaoliang Mountain and Leshan will be greatly shortened, which greatly facilitates the transportation of agricultural products. At the same time, in order to achieve the goal of Leshan's overall well-off society, the government will also make efforts to sell agricultural products. The three tier market can choose the neighboring capitals of Chongqing, Shaanxi and Sichuan. These areas are adjacent to Sichuan, ensuring that products can be transported to local sales in a short time. At the same time, the tourism industry in these areas is developed, the population is very mobile, and the economy is developed, which is very suitable for high-priced and high-quality products.

\section{B. Product strategy}

Xiaoliang Mountain has good quality agricultural products, but the transportation is inconvenient and the transportation cost is high. Therefore, the focus of agricultural production is to increase the added value of products. The following strategies can be adopted:

\section{1) Production of Wrong Season Products}

Traditionally, agricultural products are mostly seasonal. However, modern people are not satisfied with the products 
planted according to the traditional natural law, the contradiction between seasonal demand and market demand of agricultural products is becoming more and more obvious and anti-seasonal agricultural products can often be sold at higher prices, which bring huge business opportunities for the offseason agricultural products. Xiaoliang Mountain should make full use of its advantages of high mountain topography and large altitude difference; delay the spring and summer vegetables or winter vegetables cultivation in advance, and advance or delay the harvest and supply period to form distinctive mountain vegetables.

\section{2) Cultivate Fresh and Tender Products}

People's consumption habits are gradually changing, consumers began to pursue fresh and tender taste, and this change has become a popular, fresh and tender food loved by many people, which can be confirmed by the hot sale of bamboo shoots in Ebian. Ebian's oil bamboo shoots have always been famous for their fresh and tender taste, and the local government has seized this characteristic to process and sell them. Now the oil bamboo shoots are well-known agricultural products in Ebian.

\section{3) Strive for Green Organic Agricultural Products Certification \\ Certification of green organic products is equivalent to the recognition of the quality of products by the state. Nowadays, people are no longer satisfied with eating enough and the nutrition and taste is the pursuit of consumers. Many products have been advertised with high quality labels, and the marketing of Xiaoliang Mountain farm products should follow the market environment and strive for green and organic farm products certification.}

\section{4) Develop New Varieties}

Modern consumers have the pursuit of novelty and peculiar consumption psychology. We should introduce, develop and promote famous, excellent, rare and special varieties according to the market demand, and use brand-new varieties to guide the demand and open up new markets. In recent years, Xiaoliang Mountain has developed a new virus-free potato variety, which is popular with consumers because of its high yield, high quality and no virus pollution. What Xiaoliang Mountain needs to do in the future is to develop more similar products.

\section{5) Shape the Product Story}

Many quality products have their own stories. Marketing is not only selling agricultural products themselves, but also promoting the culture and feelings of the products themselves. Xiaoliang Mountain agricultural products can be sold from the national customs, origin environment, planting technology and other aspects of publicity; it can also be combined with local history, legends and myths, so that more consumers understand the product, but also endow the product more meaning. For example, the sale of Emeibian bamboo shoots can be combined with the fact that Premier Zhou gave it as a state gift to President Nixon in 1972, creating a high-end and atmospheric brand image.

\section{Branding Strategy}

The marketing direction of agricultural products in the future must be to focus on brand building and strive to create influential brands. Xiaoliang Mountain's agricultural product marketing should strengthen brand building, create a regional brand, and increase the added value of products.

\section{1) Increase Brand Awareness}

First of all, we should take advantage of the current Internet environment and do a good job in the major platforms of publicity by micro-blog, forums, television, news media and other channels to combine products with brands and publicize brands. Secondly, the local agricultural products expo can be used as a platform for publicity. National, provincial and urban areas hold agricultural products fairs every year, and Xiaoliang Mountain agricultural products brands should actively participate in the exhibition, gaining high popularity and reputation.

\section{2) Do A Good Job in Brand Declaration}

Although there are many kinds of Xiaoliang Mountain agricultural products and many local enterprises, most of them lack the awareness of trademark protection and brand awareness, resulting in a small number of local well-known enterprises. In addition to Mabian Alpine Tea Co., Ltd., Qizhiwei Food Co., Ltd., Banchang Ping Tianma and other relatively well-known enterprises, most of them are in the form of factories and do not have their own trademarks. What Xiaoliang Mountain has to do is to register trademarks in time for products with strong market advantages, such as the declaration of national geographical indications, the registration of unified regional brands, etc.

\section{Packaging Strategy}

Packaging strategy refers to the use of visual effects or product mix in the sale of products, packaging products, making its added value greatly improved.

\section{1) Highlight Product Features}

At present, the packaging of agricultural products presents two extremes: one is too simple, the other is too complex. Most consumers still have an aesthetic mentality when purchasing goods and packaging good-looking goods will be particularly attractive. The former fails to satisfy consumers' aesthetic standards and makes them lose interest in purchasing; the latter leads to confusion of consumers about what they are selling, which is often counterproductive. Imagine a box of tea, the package is bright red, how much weird. The packaging of the product should be able to highlight the product features and highlight the brand image.

\section{2) Highlight the Characteristics of the Place of Origin}

On the packaging of Yili milk, consumers can see large tracts of grassland in Inner Mongolia. There is a special piece of patchouli leaf on the packaging of the patchouli Zhengqi liquid. These packaging are combined with the producing areas, highlighting the characteristics of producing areas. People will remember the Yili milk when they see the grass. Xiaoliang Mountain has a clean environment and a combination of origin and products, making it easier for consumers to trust the quality of their products and promote them to purchase. 


\section{E. Pricing Strategy}

Xiaoliang Mountain agricultural products are positioned as high-end and high-quality agricultural products, so there should be a corresponding price strategy.

\section{1) Psychological Pricing Strategy}

Consumers who choose to buy green agricultural products are mostly out of the need for health. At the same time, they are highly educated, economically competent and have a high awareness of green agricultural products. In view of this situation, Xiaoliang Mountains agricultural products can take a high price strategy, because health is priceless, the higher the price, the better the product reflects the quality and rarity.

\section{2) Differential Pricing Strategy}

Different pricing for different quality agricultural products. High-quality agricultural products are used to open up high-end agricultural products market and the main target customers are the pursuit of high-quality products crowd; medium or medium-lower products are used to open the low-end market, and the main target customers are those who do not have high quality requirements or purchase products for the first time.

\section{3) Reputation Pricing Strategy}

Prestige pricing is characterized by setting high prices for products with a certain reputation, so that the price is higher than the value of the commodity itself; on the other hand, it allows some high-priced products to attract consumers' attention and expand the influence of other products. Gastrodia elata in Xiaoliang Mountains is of very good quality and can be priced at prestige to drive the sale of Xiaoliang Mountains.

\section{F. Promotion Strategy}

A good sales promotion program can help the product to quickly gain popularity and promote the sale of the product. Combining the culture of Xiaoliang Mountain area and other factors, the following sales promotion strategies are proposed.

\section{1) Festival Promotion}

There are many Chinese holidays, and Xiaoliang Mountain agricultural products can be combined with the Yi nationality, New Year's Day, Spring Festival, Dragon Boat Festival, Chongyang, Mid-Autumn Festival and other festivals to attract a large number of passengers, causing widespread concern. Xiaoliang Mountain can hold a large-scale promotion on the holiday day to provide consumers with free tasting at the venue, use the traffic to attract media and media reports, expand product awareness, and increase trading success opportunities.

\section{2) Offsite Promotion}

Different areas of agricultural products, even if there are similar products, but the taste will not be the same. We should promote Xiaoliang Mountain's farm products elsewhere so that specialty farm products can reach the national market. The key points of this method are: (1) identify the target customers. Living habits vary greatly from region to region. Target customer groups of Xiaoliang Mountains agricultural products should be identified and promotions should be focused on some areas to gradually open up the market. (2) Focus on training the professional quality of promotional staff in different places. Promotional staffs in different places are more stringent. Not only should we fully understand the characteristics of the products, but also understand the local living habits and eating habits.

\section{3) Theme Promotion}

This promotion is suitable for large supermarkets and exhibitions. On the one hand, the theme of Xiaoliang Mountain special agricultural products is centered on the theme, focusing on the promotion of the location, so that the promotion point stands out among the many exhibition booths, and can combine local musical instruments and performances to attract the attention of consumers. On the other hand, on the exhibition of products, the theme is divided into categories orderly, so that consumers can see what products are available at a glance, which is convenient for purchase.

\section{G. Channel Strategy}

\section{1) Cooperation with Major Supermarket Chains}

With the increasing demand for green and pollution-free food, supermarkets can better guarantee the quality of products. Shopping for agricultural products in supermarkets has become a normal life for people. Xiaoliang Mountain should strengthen cooperation with local large supermarket chains. The cooperative purchased products and sold to supermarkets, during which the middle dealers will be much less. Without the increase of middleman's price, consumers will pay lower price to get the products, and truly get good quality at low price.

\section{2) Increase Network Marketing Efforts}

It is the era of e-commerce; Xiaoliang Mountain agricultural products should use the Internet to develop the market. Compared with offline marketing mode, online marketing can increase transaction opportunities and effectively reduce sales costs; meanwhile, through large data analysis, market information and market dynamic changes can be accurately obtained, which is conducive to farmers to make correct decisions. Xiaoliang Mountain farmers can use the existing network platform for sales; and they can build their own websites to publish information on them, such as Farming Sales Network, Yigu Network and other websites. In addition, in the promotion of agricultural products, it is necessary to make more use of the existing two platforms for publicity. Because these two platforms spread quickly, have a wide audience, and have low publicity costs and the information published on these two platforms is free, making the profit margin of farmers more.

\section{CONCLUSION}

The task of poverty alleviation in poverty-stricken areas of ethnic minorities is very arduous. Helping farmers to increase the output of agricultural products can only solve the problem of increasing production, but can not make farmers rich. Establishing effective marketing strategies for agricultural products can promote farmers to reduce poverty and increase income. It is an optional and precise path for poverty alleviation and an effective way out for minority areas to get rid of poverty and become rich. As the quality of life becomes more demanding and organic farm products become the darling of the market, the traditional disadvantages of the Xiaoliang Mountains region are gaining ground today. Xiaoliang 
Mountain agricultural products should seize market opportunities, make use of the preferential policies of the country's precision poverty alleviation and the support of various funds and technologies, develop local characteristic agriculture, rationally select target markets, innovate product strategies, brand strategies, packaging strategies, price strategies, channel strategy and promotion strategies, etc., to solve the problem of difficult sales of agricultural products, help farmers increase production and income, achieve poverty alleviation and promote the development of ethnic areas.

\section{REFERENCES}

[1] Li Wei \& Ye Xingjian. Precise Poverty Alleviation in Rural Areas: Analysis of Theoretical Foundation and Practice Situation-On the Construction of Compound Poverty Alleviation Governance System[J]. Journal of Fujian Administration Institute, 2015(2):26-33 (In Chinese)

[2] Deng Weijie. Difficulties, Countermeasures and Path Selection of Accurate Poverty Alleviation[J].Rural Economy,2014(6):78-81 (In Chinese)

[3] Yuan Hua. Constructing the Circulation Channel of Agricultural Products with Cooperative Organizations as the Link [J]. Scientific and Technological Information Development and Economy, 2005, (05): 140141. [2017-10-06]. (In Chinese)

[4] Li Kaixu. Analysis of the Ways of Branding of Agricultural Products[J].Modern Agriculture,2011,(02):36-37. [2017-10-07] (In Chinese)

[5] Li Haili. Characteristics of Agricultural Products Brand Construction in China[J].Rural Economy and Technology,2012,23(05):84-86. [2017-1007] (In Chinese) 